\title{
Quantity, particle size, and histologic composition of embolic debris collected in a distal protection filter after carotid angioplasty and stenting: Correlation with patient characteristics, timing of carotid artery stenting, and procedural details
}

Jorinde H. H. van Laanen, MD, ${ }^{\mathrm{a}}$ Joke M. Hendriks, MD, PhD, ${ }^{\mathrm{a}}$ Hence J. M. Verhagen, MD, PhD, ${ }^{\mathrm{a}}$ and Heleen M. M. van Beusekom, PhD, FESC, ${ }^{\text {b }}$ Rotterdam, The Netherlands

The occurrence of distal embolization during carotid artery stenting (CAS) is a major complication. Determining the preoperative risk of embolization may lead to improved patient selection and outcome of CAS. This study examined the quantity, particle size, and histologic composition of embolic debris collected in a distal protection filter and its possible correlation with patient characteristics, timing of CAS, and procedural details.

\section{CLINICAL SUMMARY \\ Subjects}

Patients who underwent a CAS procedure during a 17-month period in which a SPIDER Embolic Protection Device (EPD) (ev3 Endovascular Inc, Plymouth, Minn) was used were included. Patient demographics, cardiovascular risk factors, neurologic symptoms, and time interval between symptoms and CAS were retrospectively recorded.

\section{Procedure}

CAS was performed according to the standardized protocol in our center as described previously. ${ }^{1}$ This protocol also dictates the antiplatelet regimen.

From the Department of Vascular Surgery, ${ }^{\text {a }}$ Erasmus Medical Center, Rotterdam, The Netherlands; and Department of Experimental Cardiology, ${ }^{b}$ Erasmus Medical Center, Faculteitsgebouw, Rotterdam, The Netherlands.

Disclosures: Authors have nothing to disclose with regard to commercial support. Received for publication Nov 11, 2012; revisions received March 6, 2013; accepted for publication March 15, 2013; available ahead of print April 15, 2013.

Address for reprints: Jorinde H. H. van Laanen, MD, Department of Vascular Surgery, Erasmus Medical Center, Postbus 2040, 3000 CA, Rotterdam, The Netherlands (E-mail: j.vanlaanen@erasmusmc.nl).

J Thorac Cardiovasc Surg 2013;146:492-5

$0022-5223 / \$ 36.00$

Copyright $\Subset 2013$ by The American Association for Thoracic Surgery http://dx.doi.org/10.1016/j.jtcvs.2013.03.024
TABLE 1. Patient $(n=55)$ and lesion $(n=59)$ characteristics

\begin{tabular}{lc}
\hline & Patients, $\mathbf{n}(\%)$ \\
\hline Age, y & Mean, $67.2($ range, $47-89)$ \\
Male sex & $36(66)$ \\
Hypertension & $43(78)$ \\
Hypercholesterolemia & $41(75)$ \\
Diabetes & $9(16)$ \\
Cardiac disease & $13(24)$ \\
Chronic renal insufficiency & $9(16)$ \\
Smoking history & $39(71)$ \\
\hline & \\
& Lesions, $\mathbf{n}(\%)$ \\
\hline Asymptomatic & $5(8.5)$ \\
Symptomatic & $54(91.5)$ \\
Amaurosis fugax & $8(14)$ \\
Retinal infarction & $1(2)$ \\
Transient ischemic attack & $28(48)$ \\
Stroke & $17(29)$ \\
Onset of symptoms before CAS & \\
$0-28$ d & $35(59)$ \\
$>28$ d & $24(41)$ \\
Contralateral occlusion & $10(17)$ \\
Percent stenosis & \\
$50 \%-69 \%$ & $4(7)$ \\
$70 \%-99 \%$ & $55(93)$ \\
\hline CAS, C &
\end{tabular}

CAS, Carotid artery stenting.

\section{Histopathology and Filter Analysis}

Debris was photographed before (Figure 1, $A$ ) and after (Figure 1, $B$ ) removal from the EPD. Clemex image analysis software (Clemex Technologies Inc, Longueuil, Canada) was used to analyze the number and size of the particles.

Consecutive series of paraffin sections were stained with hematoxylin-eosin as a routine stain, resorcin-fuchsin for

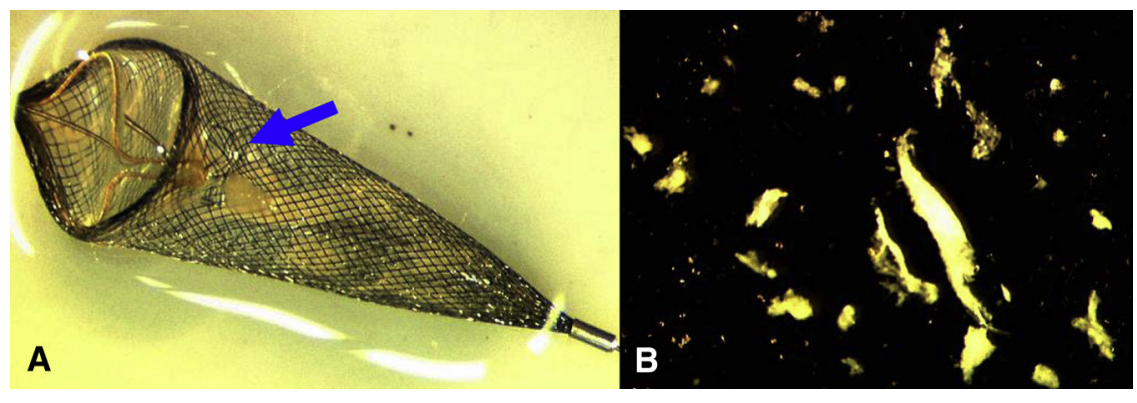

FIGURE 1. Macroscopic images of EPD containing embolic material (A, arrow) and debris as retrieved from EPD (B). 
TABLE 2. Patient and procedural characteristics of 44 cases with embolic particles in the Embolic Protection Device and number and size of particles

\begin{tabular}{|c|c|c|c|c|c|}
\hline & $\mathbf{N}=(\%)$ & No. of particles, median (min-max) & $P$ value & $\begin{array}{l}\text { Length of particles, median } \\
\text { (min-max) }\end{array}$ & $P$ value \\
\hline \multicolumn{6}{|l|}{ Age (y) mean, 67.6 (47-89) } \\
\hline Less than or equal to mean & $22(50)$ & $8(1-29)$ & \multirow[t]{2}{*}{.51} & $670(60-6045)$ & \multirow[t]{2}{*}{.09} \\
\hline Greater than mean & $22(50)$ & $9(1-47)$ & & $609(79-9423)$ & \\
\hline \multicolumn{6}{|l|}{ Sex } \\
\hline Male & $29(65.9)$ & $10(1-47)$ & \multirow[t]{2}{*}{.98} & $615(60-9423)$ & \multirow[t]{2}{*}{.31} \\
\hline Female & $15(34.1)$ & $7(1-29)$ & & $728(79-6771)$ & \\
\hline \multicolumn{6}{|l|}{ Hypertension } \\
\hline Yes & $38(86.4)$ & $9.5(1-31)$ & \multirow[t]{2}{*}{.37} & $684(60-9423)$ & \multirow[t]{2}{*}{.013} \\
\hline No & $6(13.6)$ & $3.5(1-47)$ & & $474(129-3681)$ & \\
\hline \multicolumn{6}{|l|}{ Hypercholesterolemia } \\
\hline Yes & $30(68.2)$ & $10(1-24)$ & \multirow[t]{2}{*}{.31} & $653(60-6771)$ & \multirow[t]{2}{*}{.43} \\
\hline No & $14(31.8)$ & $5.5(1-47)$ & & $621(79-9423)$ & \\
\hline \multicolumn{6}{|l|}{ Diabetes } \\
\hline Yes & $9(20.5)$ & $13(3-31)$ & \multirow[t]{2}{*}{.5} & $782(135-9423)$ & \multirow[t]{2}{*}{.018} \\
\hline No & $35(79.5)$ & $8(1-47)$ & & $615(60-6045)$ & \\
\hline \multicolumn{6}{|l|}{ Cardiac disease } \\
\hline Yes & $10(22.7)$ & $9.5(3-24)$ & \multirow[t]{2}{*}{.83} & $707(60-6771)$ & \multirow[t]{2}{*}{.17} \\
\hline No & $34(77.3)$ & $8.5(1-47)$ & & $629(79-9423)$ & \\
\hline \multicolumn{6}{|l|}{ Chronic renal insufficiency } \\
\hline Yes & $9(20.5)$ & $8(1-24)$ & \multirow[t]{2}{*}{.77} & $706(147-4676)$ & \multirow[t]{2}{*}{.38} \\
\hline No & $35(79.5)$ & $9(1-47)$ & & $636(60-9423)$ & \\
\hline \multicolumn{6}{|l|}{ Smoking history } \\
\hline Yes & $31(70.5)$ & $7(1-47)$ & .029 & $643(60-9423)$ & .42 \\
\hline No & $13(29.5)$ & $14(4-29)$ & & $643(79-6771)$ & \\
\hline Asymptomatic & & & & & \\
\hline Yes & $3(6.8)$ & $3(1-14)$ & .23 & $546(169-1728)$ & .76 \\
\hline No & $41(93.2)$ & $9(1-47)$ & & $645(60-9423)$ & \\
\hline Symptomatic & & & & & \\
\hline Amaurosis fugax & $4(9.1)$ & $4(1-21)$ & .24 & $650(213-4095)$ & .22 \\
\hline Transient ischemic attack & $23(52.3)$ & $8(1-31)$ & & $669(79-9423)$ & \\
\hline Stroke & $14(31.8)$ & $11.5(2-47)$ & & $606(60-6771)$ & \\
\hline Onset of symptoms before $\mathrm{CA}$ & & & & & \\
\hline $0-28 \mathrm{~d}$ & $28(64)$ & $10(1-47)$ & .048 & $653(60-9423)$ & \\
\hline$>28 \mathrm{~d}$ & $16(36)$ & $4(1-23)$ & & $615(135-4676)$ & .51 \\
\hline Duration CAS & & & & & \\
\hline$<2 \mathrm{~h}$ & $21(48)$ & $8(1-31)$ & .46 & 695 (60-9423) & .25 \\
\hline$\geq 2 \mathrm{~h}$ & $23(52)$ & $10(2-47)$ & & $603(79-6045)$ & \\
\hline Predilation & & & & & \\
\hline Yes & $40(91)$ & $8.5(1-47)$ & .87 & $630(60-9423)$ & .52 \\
\hline No & $4(9)$ & $9(1-19)$ & & $838(125-4102)$ & \\
\hline Postdilation & & & & & \\
\hline Yes & $41(93)$ & $9(1-47)$ & .89 & $633(60-9423)$ & .14 \\
\hline No & $3(7)$ & $7(5-13)$ & & $881(160-4676)$ & \\
\hline Stent type & & & & & \\
\hline Acculink & $30(68)$ & $8(1-47)$ & .60 & $599(79-6045)$ & .21 \\
\hline Protege & $7(16)$ & $13(3-31)$ & & $714(60-9423)$ & \\
\hline Other & $7(16)$ & $10(4-21)$ & & $615(135-4676)$ & \\
\hline
\end{tabular}

CAS, Carotid artery stenting.

collagen and elastin, and von Kossa for collagen and calcified tissue to study the particles at different depths. Debris was classified as thrombus (containing platelets, erythrocytes, and fibrin), atheroma (fibrous matrix, cholesterol clefts, and foam cells), and calcified tissue on the basis of morphologic criteria.

\section{Statistical Analysis}

Data were analyzed using SPSS software (SPSS Statistics 17.0; SPSS Inc, Chicago, Ill). Continuous variables were expressed as median (minimum-maximum) in case normality could not be assumed and compared with nonparametric tests. 


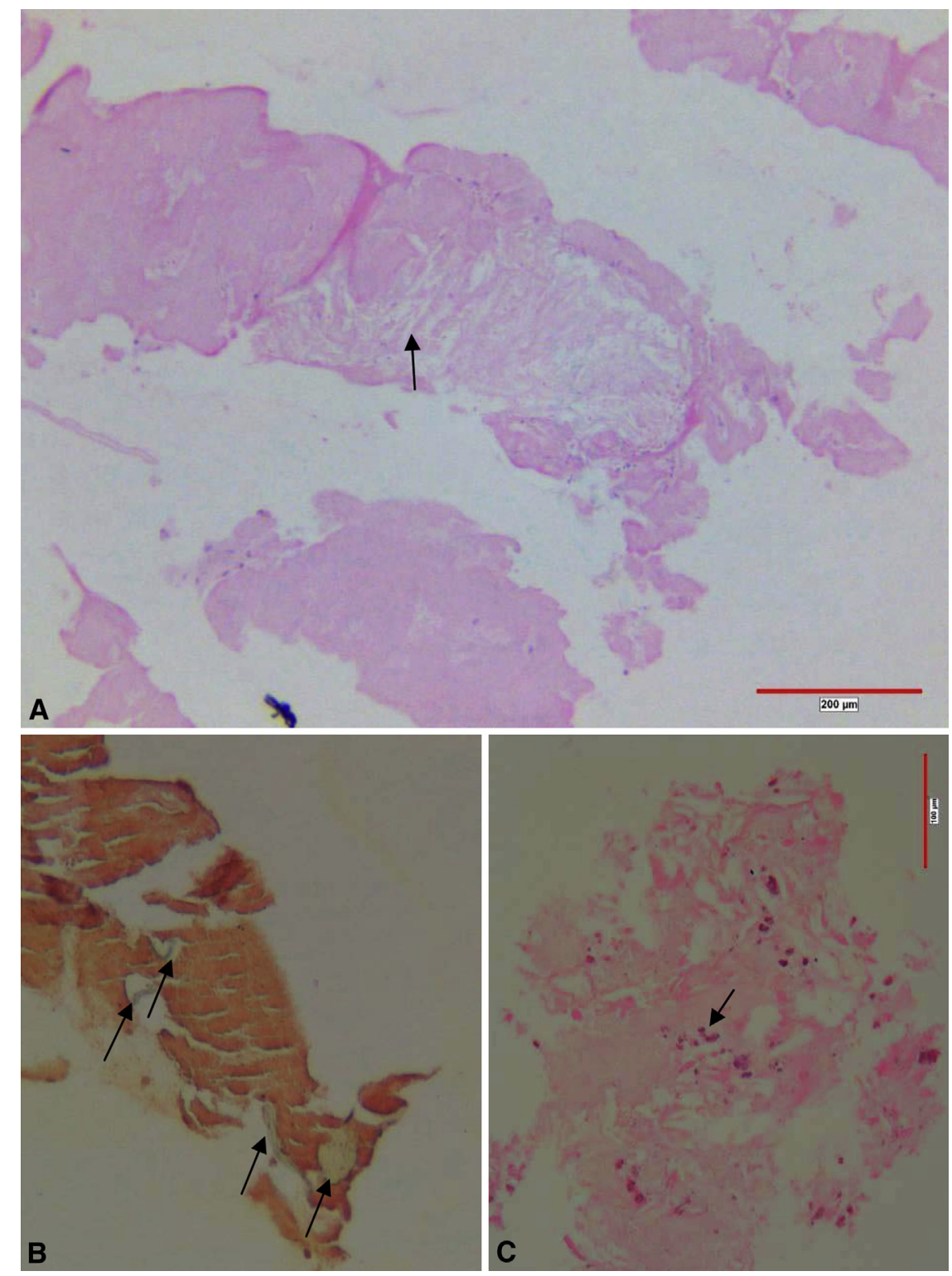

FIGURE 2. Histology of embolic debris contains both thrombus and atheromatous material characterized by the cholesterol clefts (A, arrows). Within the debris, polymeric material (B, arrows) and calcific nodules (C, arrows) were observed. A and C, Hematoxylin-eosin. B, von Kossa.

\section{RESULTS}

\section{Patients and Procedures}

Demographics of the 55 included patients and details of the 59 treated stenotic lesions in these patients are presented in Table 1.

\section{Histopathology}

Macroscopic evaluation detected particles in 44 of the 59 collected filters (75\%) (Figure 1). Table 2 represents patient and procedural details of these cases and the number and size of the detected particles. The EPD in patients who smoked showed a significantly lower number of particles compared with nonsmokers ( 7 vs $14, P=.029$ ). The number of particles was significantly higher when CAS was performed in the first 4 weeks after the qualifying neurologic event (10 vs $4, P=.048$ ).

Qualitative assessment of histologic sections showed determinable embolic debris in $36(82 \%)$ of the processed filters. Embolic particles consisted of atheromatous debris in 13 cases $(36 \%)$, thrombus in 16 cases $(44 \%)$, and calcified tissue in 7 cases (19\%) (Figure 2). Atheromatous plaques generated a significantly higher number of particles (median $14, P=.01$ ).

\section{DISCUSSION}

Despite the use of protection devices, cerebral embolization has been shown by transcranial Doppler and diffusionweighted magnetic resonance imaging. ${ }^{2,3}$ Although most of the clinical implications of detected microemboli remain 
undefined, association with deterioration in cognitive function 6 months after CAS has been reported. ${ }^{4}$ Currently, no protection device can completely prevent distal embolization. Furthermore, dislodgement of embolic debris can occur during guidewire manipulation and protection device positioning or removal. Determining the risk factors for embolization could lead to a better patient selection, improving outcomes of CAS.

Unstable, echolucent atherosclerotic plaques have been associated with increased embolic potential and increased risk of stroke in CAS. ${ }^{5}$ This study confirms the increased embolic potential, because we found a significantly higher number of embolic particles when CAS was performed in the first weeks after symptoms and a significantly higher number of particles in atheromatous plaques.

Older age, hypertension, hypercholesterolemia, coronary artery disease, symptomatic lesions, number of balloon dilations, and stent diameter have unequivocally been associated with increased embolic potential. In this study, we found only smoking to be negatively correlated with the number of dislodged particles during CAS. A possible explanation for this finding is that plaque composition in smokers differs from nonsmokers because of different etiology, and these plaques could be more stable.

Because of the method of histologic processing and section staining, not all filters containing embolic debris appeared in the qualitative analysis. In addition to the small sample size, this is a limitation of this study.

\section{CONCLUSIONS}

The detailed analysis of embolic debris and the findings that lesion characteristics and timing of intervention seem to be the most important factors influencing distal embolization during CAS and contribute to further understanding the mechanism of embolization and better patient selection.

\section{References}

1. Flach HZ, Ouhlous M, Hendriks JM, van Sambeek MRHM, Veenland JF Koudstaal PJ, et al. Cerebral ischemia after carotid intervention. J Endovasc Ther. 2004;11:251-7.

2. Bonati LH, Jongen LM, Haller S, and the ICSS-MRI study group. New ischaemic brain lesions on MRI after stenting or endarterectomy for symptomatic carotid stenosis: a substudy of the International Carotid Stenting Study (ICSS). Lancet Neurol. 2010;9:353-62.

3. Timaran CH, Rosero EB, Martinez AE, Ilarraza A, Modrall JG, Clagett GP. Ath erosclerotic plaque composition assessed by virtual histology intravascular ultrasound and cerebral embolization after carotid stenting. J Vasc Surg. 2010;52: 1188-94.

4. Altinbas A, van Zandvoort MJ, van den Berg E, Jongen LM, Algra A, Moll FL, et al. Cognition after carotid endarterectomy or stenting: a randomized comparison. Neurology. 2011;77:1084-90.

5. Topakian R, Strasak AM, Sonnberger M, Haring HP, Nussbaumer K, Trenkler J, et al. Timing of stenting of symptomatic carotid stenosis is predictive of 30-day outcome. Eur J Neurol. 2007;14:672-8.

\title{
Is there any benefit in using awake anesthesia with thoracic epidural in thoracoscopic talc pleurodesis?
}

\author{
Eugenio Pompeo, MD, ${ }^{\mathrm{a}}$ and Mario Dauri, MD, ${ }^{\mathrm{b}}$ for the Awake Thoracic Surgery Research Group, \\ Rome, Italy
}

\section{Supplemental material is available online.}

General anesthesia is commonly used for video-assisted thoracic surgery (VATS) with talc pleurodesis, although use of regional anesthesia in the awake patient might

\footnotetext{
From the Departments of Thoracic Surgery ${ }^{\mathrm{a}}$ and Anesthesiology and Intensive Care, ${ }^{\mathrm{b}}$ Policlinico Tor Vergata University, Rome, Italy.

Disclosures: Authors have nothing to disclose with regard to commercial support.

The Awake Thoracic Surgery Research Group is listed in the Appendix.

Received for publication Dec 5, 2012; revisions received March 19, 2013; accepted for publication March 25, 2013; available ahead of print April 22, 2013.

Address for reprints: Eugenio Pompeo, MD, Section of Medical and Surgical Lung Diseases, Department of Biomedicine and Prevention, Tor Vergata University,

Via Montpellier 1, 00133 Rome, Italy (E-mail: pompeo@med.uniroma2.it).

J Thorac Cardiovasc Surg 2013;146:495-7

$0022-5223 / \$ 36.00$

Copyright (c) 2013 by The American Association for Thoracic Surgery

http://dx.doi.org/10.1016/j.jtcvs.2013.03.038
}

improve outcomes. ${ }^{1,2}$ The purpose of this randomized study is to compare the hospital discharge of patients undergoing VATS with talc pleurodesis using thoracic epidural or general anesthesia.

\section{CLINICAL SUMMARY}

Forty patients with malignant pleural effusion were randomized to undergo VATS with talc pleurodesis by awake anesthesia with thoracic epidural (awake group, $\mathrm{N}=20$ ) or general anesthesia and 1-lung ventilation (control group, $\mathrm{N}=20$ ) (ClinicalTrials.gov registration No. NCT01469728). The study was approved by the Policlinico Tor Vergata University ethical committee, and written informed consent was obtained by the patients. Eligibility criteria are summarized in Table E1.

In the awake group, the thoracic epidural catheter was inserted at the T4 level for continuous infusion of ropivacaine 